\title{
Clinical Correlates of Alcohol Use Disorder in Depressed Patients with Unipolar and Bipolar Disorder
}

\author{
Minseok Hong${ }^{1}$, Tae Hyon $\mathrm{Ha}^{2} \bowtie$, Suyeon $\mathrm{Lee}^{2}$, Sunghee $\mathrm{Oh}^{2}$, and Woojae Myung ${ }^{2}$ \\ ${ }^{1}$ Department of Psychiatry, Seoul National University College of Medicine, Seoul, Republic of Korea \\ ${ }^{2}$ Mood Disorders Clinic \& Clinical Affective Neuroscience Laboratory, Department of Psychiatry, Seoul National University Bundang Hospital, \\ Seongnam, Republic of Korea
}

\begin{abstract}
Objective Alcohol use disorder (AUD) is one of the most frequent comorbid conditions in mood disorders. We aimed to examine the relationships between clinical phenotypes of acutely depressed subjects and co-occurring AUD.

Methods Clinical assessment including diagnosis of mood disorder and co-occurring AUD, the severity of depressive or manic symptoms, and affective temperaments were conducted in 137 subjects suffering from a major depressive episode. According to the presence of AUD, clinical variables were compared between the two groups. Using binary logistic regression models, the effects of mood symptoms and affective temperaments on the risk of AUD were determined.

Results Severity of manic symptoms, suicidal ideation, and childhood trauma were higher in the AUD group than in the non-AUD group. Scores for irritable and hyperthymic temperament were higher and the score for anxious temperament was lower in the AUD group. In regression models adjusting confounders, anxious temperament was an independent protector against AUD. On the other hand, the diagnosis of bipolar disorder and the irritable manic symptom dimension increased the risk of AUD.

Conclusion Anxious temperament decreased the AUD risk, whereas irritable manic symptoms increased the risk during depression. AUD in mood disorders may be an expression of manic psychopathology.

Psychiatry Investig 2019;16(12):926-932
\end{abstract}

Key Words Major depressive episode, Alcohol use disorder, Bipolar disorder, Affective temperaments, Manic symptoms dimension.

\section{INTRODUCTION}

Alcohol use disorder (AUD) is over-represented in subjects with mood disorders and has a negative impact on the course of the mood disorder. Prevalence rates of AUD among subjects with bipolar disorder (BD) range from $30 \%$ to $60 \%{ }^{1-5}$ and those among subjects with major depressive disorder (MDD) from $30 \%$ to $40 \%{ }^{6-8}$ The presence of a comorbid AUD in BD has been known to be associated with an earlier onset of the mood symptoms, ${ }^{4}$ more relapses, ${ }^{9,10}$ increased suicide risks, ${ }^{11}$ violent behaviors, ${ }^{12}$ more hospitalizations, ${ }^{1}$ and treatment nonadherence. ${ }^{13}$ Similarly, comorbid AUD in MDD increases disease burden, such as increased suicide risks or other unnatural

Received: July 18, 2019 Revised: October 7, 2019

Accepted: October 27, 2019

$\triangle$ Correspondence: Tae Hyon $\mathrm{Ha}, \mathrm{MD}, \mathrm{PhD}$

Department of Psychiatry, Seoul National University Bundang Hospital 82 Gumi-ro 173beon-gil, Bundang-gu, Seongnam 13620, Republic of Korea Tel: +82-31-787-7434, Fax: +82-31-787-4058, E-mail: hatti@snu.ac.kr

(ac) This is an Open Access article distributed under the terms of the Creative Commons Attribution Non-Commercial License (https://creativecommons.org/licenses/bync/4.0) which permits unrestricted non-commercial use, distribution, and reproduction in any medium, provided the original work is properly cited. death, ${ }^{14}$ lower functioning, ${ }^{8}$ and worse outcome, ${ }^{15}$ as well.

Given the paucity of evidence supporting effective treatments, ${ }^{16-18}$ subjects with AUD and depression present a big clinical challenge to clinicians. Hypothetical explanations for the relationship between the two conditions are conflicting. The self-medication hypothesis explains substance use as an attempt to alleviate mood symptoms, while other hypothesis postulates that repeated substance administration causes brain change to mediate mood disorders. ${ }^{19,20}$ Another potential perspective assumes that both conditions share common neurobiological vulnerabilities. ${ }^{21}$ To better understand the interactive and bidirectional relationships between the two conditions, and thus to develop efficient management strategies, many questions remaining unanswered should be more extensively investigated. One pressing question is exploring phenomenological correlates of AUD in mood disorders. Though several risk indicators including male gender, earlier onset, polysubstance use and family history of AUD ${ }^{2,6,22}$ were found, characteristics of mood symptoms have not been fully explored yet. Distinct phenotypic expressions of mood disorders may have differential relationships with AUD, which 
would allow to identify better diagnoses and treatments.

To our knowledge, few studies have analyzed mood symptoms that were related to AUD. More depressive symptoms were reported in MDD comorbid with AUD in general population ${ }^{23,24}$ and clinical samples. ${ }^{25,26}$ However, findings of these studies that used different measures are quite inconsistent to limit their generalization. Furthermore, no studies have explored the relation of manic symptoms to comorbid AUD.

Affective temperaments are a collection of biologically determined traits concept of which has been developed according to 'basic states' described by Kraepelin. ${ }^{27}$ They are postulated as a continuum of several conditions encompassing normal personality functioning, subclinical affective state, and predisposition for more severe mood episodes. ${ }^{28}$ Therefore, affective temperaments can serve as an important phenotype in mood disorder that complements symptom expressions of a mood episode. To date, little has focused on relations of affective temperaments to AUD in mood disorders. Only one study has assessed the relations and found that hyperthymic and irritable temperaments contributed to the association between AUD and $\mathrm{BD}^{29}$ On the other hand, in AUD or other substance use disorders, cyclothymic, depressive, and irritable temperaments were implicated. ${ }^{30-33}$

The current study aimed to examine the relationships between clinical phenotypes of acute depressive episodes and co-occurring AUD, using depressive or manic symptom rating scales and measure of affective temperaments. To encompass diverse clinical features of acute depressive episodes, subjects with a major depressive episode regardless of subtypes of mood disorder were included. Childhood adversities are one of the most significant risk factors for AUD as well, and are thought to be a constitutional basis and a possible covariate of both addiction and mood symptoms. ${ }^{34-37}$ Therefore, to clarify clinical correlates of AUD in mood disorders, a measure of childhood trauma should be included as a potential confounder. We hypothesized that AUD would be more frequent in $\mathrm{BD}$ than in MDD and that phenotypes related to $\mathrm{BD}$ would predict AUD in acutely depressed subjects.

\section{METHODS}

\section{Subjects}

The sample consisted of 89 subjects with BD and 48 subjects with MDD. Subjects were recruited from the outpatient clinic or inpatient unit of the Mood Disorders Clinic at Seoul National University Bundang Hospital and met the DSM-IVTR criteria for BD (bipolar I disorder, bipolar II disorder, and bipolar disorder NOS) or MDD, using the Mini-International Neuropsychiatric Interview (MINI). ${ }^{38}$ Inclusion criteria were an absence of any lifetime history of significant neurological or medical illnesses, age between 19 and 80, the fulfillment of criteria for a major depressive episode and the score of the Hamilton Depression Rating Scale (HAMD) 8 or higher. This study was approved by the Institutional Review Board (B1902/524-103).

\section{Clinical assessment}

The obtained clinical variables included basic demographic information such as gender, age, and duration of illness. The severity of depressive or manic symptoms was measured using the HAMD and the Young Mania Rating Scale (YMRS). The severity of suicide risk was measured using the Scale for Suicide Ideation (SSI) ${ }^{39}$ Experiences of childhood trauma were measured using the Childhood Trauma Questionnaire Korean version (CTQ). ${ }^{40}$ Diagnosis of AUD was made when DSM-IV-TR criteria for alcohol dependence and/or abuse were met within the last 12 months from the assessment, to ensure the current comorbidity. All subjects with AUD were having alcohol misuse at the time of evaluation.

Affective temperaments were measured using the short version of the Temperament Evaluation of Memphis, Pisa, Paris and San Diego-autoquestionnaire (TEMPS-A) that has 39 items assessing cyclothymic, depressive, irritable, hyperthymic and anxious temperaments. ${ }^{41}$ The questionnaire was translated by the authors (TH Ha \& S Oh).

\section{Statistical analysis}

Clinical variables between the groups with AUD and without AUD were compared using the Student's t-test and Chisquare test. Mixed depressive state was defined as 3 or more YMRS items were 2 or above.

To find out significant predictors and to adjust possible covariates, we tested two bivariate logistic regression models. Model 1 was intended to assess the risk of diagnosis, the severity of mood symptoms and affective temperaments. Childhood trauma and suicidal ideation were added as covariates because these factors are known to relate both to mood disorders and addictive disorders. ${ }^{42-45}$ Model 2 was aimed at examining the risk of dimensions of depressive symptoms and manic symptoms. Each of the dimensions was quoted from previous factor analytic studies for HAMD ${ }^{46}$ and YMRS. ${ }^{47}$ Somatic anxiety, psychic anxiety, core depression, and anorexia were dimensions of depressive symptoms from the HAMD, and irritable mania, elated mania, and psychotic mania were dimensions of manic symptoms from the YMRS. Gender, age, and diagnosis of mood disorder were adjusted to complete these models. For all the statistical procedures, IBM SPSS Statistics ver. 25 (IBM Corp. Armonk, NY, USA) was used and significance was set as $\mathrm{p}<0.05$. 


\section{RESULTS}

Among 137 subjects, 29 (21.2\%) had co-occurring AUD. The proportion of subjects having AUD was higher in the BD group (27.0\%) than in the MDD group (10.4\%) $\left(\chi^{2}=5.118\right.$, $\mathrm{p}=0.024)$. Proportions of the BD subtypes were not different between the AUD and non-AUD groups. The AUD group had a higher YMRS mean score $(\mathrm{t}=-3.567, \mathrm{p}=0.001)$, compared to the subjects without AUD. The rate of mixed depressive state, defined as 3 or more YMRS items above 1, was found to be $33.6 \%$ (12.5\% of MDD and $44.9 \%$ of BD) and was higher in the AUD group $\left(\chi^{2}=7.693, \mathrm{p}=0.006\right)$. The mean scores for irritable $(\mathrm{t}=-2.641, \mathrm{p}=0.010)$ and hyperthymic temperaments $(\mathrm{t}=-2.624$, $\mathrm{p}=0.032)$ were higher, and the mean score for anxious temperament was lower $(\mathrm{t}=2.164, \mathrm{p}=0.032)$ in the AUD group than in the non-AUD group. The AUD group showed more suicidal ideation $(t=-2.252, p=0.026)$ and reported more childhood adversities $(\mathrm{t}=-4.027, \mathrm{p}<0.001)$ than the non-AUD group. Gender, age, and the severity of depressive symptoms did not differ between the two groups (Table 1).

When potential confounders were adjusted, only the anxious temperament was significant in the regression model 1 (OR=0.373, 95\% CI: 0.206-0.675, p=0.001). Among confounding variables, age and childhood trauma were significant in this model (Table 2).

In regression model 2 to test the relationships between specific mood symptom dimensions and AUD, the irritable mania dimension significantly predicted AUD (OR=1.412, 95\% CI: $1.162-1.717, \mathrm{p}=0.001)$. None of the dimensions of depressive symptoms were significant in this model. Among confounders, the diagnosis of $\mathrm{BD}$ was significant $(\mathrm{OR}=3.677$, 95\% CI: 1.031-13.119, $\mathrm{p}=0.045$ ) (Table 3).

\section{DISCUSSION}

To our knowledge, the current study is the first to explore specific mood symptoms and affective temperaments in depressed subjects comorbid with AUD. The main findings of this study were that a diagnosis of BD, specific mood symptoms and affective temperaments were risk factors for co-occurring AUD in depressed subjects. Specifically, in subjects with depression, irritable manic symptoms increased the risk of AUD while the anxious temperament decreased it.

$27 \%$ of BD and $10 \%$ of MDD subjects in this study had a co-occurring AUD. Compared to previous studies, ${ }^{1-8}$ those rates were lower, which may be related to the characteristics of our sample. Subjects in our study were likely to be in their mid-thirties and approximately 10 years younger than previous studies. SUD may be a complication during the course of mood disorder, given the cumulative elevation of the comor-
Table 1. Demographic and clinical characteristics of the subjects

\begin{tabular}{|c|c|c|c|c|}
\hline & $\begin{array}{c}\text { Without } \\
\text { AUD } \\
(\mathrm{N}=108)\end{array}$ & $\begin{array}{c}\text { With } \\
\text { AUD } \\
(\mathrm{N}=29)\end{array}$ & Statistics & $\mathrm{p}$ \\
\hline \multicolumn{5}{|c|}{ Demographic characteristics } \\
\hline Female (\%) & $81(75.0)$ & $21(72.4)$ & $\chi^{2}=0.080$ & 0.777 \\
\hline Age & $35.9 \pm 12.4$ & $34.2 \pm 11.0$ & $\mathrm{t}=0.682$ & 0.497 \\
\hline Duration of illness & $9.0 \pm 9.1$ & $9.9 \pm 10.0$ & $\mathrm{t}=-0.479$ & 0.633 \\
\hline Diagnosis of BD (\%) & $65(60.2)$ & $24(82.8)$ & $\chi^{2}=5.118$ & 0.024 \\
\hline Subtypes of BD (\%) & & & $\chi^{2}=1.633$ & 0.442 \\
\hline BD I & $5(4.6)$ & $4(13.8)$ & & \\
\hline BD II & $43(39.8)$ & $15(51.7)$ & & \\
\hline BD NOS & $17(15.7)$ & $5(17.2)$ & & \\
\hline $\begin{array}{l}\text { Mixed depressive } \\
\text { state }\end{array}$ & $30(27.8)$ & $16(55.2)$ & $\chi^{2}=7.693$ & 0.006 \\
\hline
\end{tabular}

Severity of mood symptoms

$\begin{array}{lrrrr}\text { HAMD } & 17.7 \pm 6.4 & 19.7 \pm 7.1 & \mathrm{t}=-1.427 & 0.156 \\ \text { YMRS } & 5.6 \pm 4.5 & 9.1 \pm 5.6 & \mathrm{t}=-3.567 & 0.001 \\ \text { Affective temperament } & & & & \\ \text { Cyclothymic } & 6.4 \pm 3.5 & 7.7 \pm 3.2 & \mathrm{t}=-1.773 & 0.079 \\ \text { Depressive } & 3.7 \pm 2.5 & 4.0 \pm 2.4 & \mathrm{t}=-0.751 & 0.454 \\ \text { Irritable } & 2.4 \pm 2.3 & 3.7 \pm 2.4 & \mathrm{t}=-2.641 & 0.009 \\ \text { Hyperthymic } & 2.7 \pm 2.3 & 4.0 \pm 2.7 & \mathrm{t}=-2.624 & 0.010 \\ \text { Anxious } & 1.7 \pm 1.1 & 1.1 \pm 1.2 & \mathrm{t}=2.164 & 0.032\end{array}$

Suicidal ideation, childhood trauma

\begin{tabular}{lllll} 
SSI & $12.8 \pm 9.1$ & $17.0 \pm 8.5$ & $\mathrm{t}=-2.252$ & 0.026 \\
CTQ & $59.3 \pm 18.6$ & $75.7 \pm 22.4$ & $\mathrm{t}=-4.027$ & 0.000 \\
\hline
\end{tabular}

AUD: alcohol use disorder, BD: bipolar disorder, BD I: bipolar I disorder, BD II: biapolar II disorder, BD NOS: bipolar disorder NOS, HAMD: Hamilton Depression Rating Scale, YMRS: Young Mania Rating Scale, SSI: Scale for Suicide Ideation, CTQ: Childhood Trauma Questionnaire

bidity rates. ${ }^{8}$ In line with this assumption, our regression model revealed that age increased the risk of AUD. Male gender was usually considered as a risk factor for AUD in mood disorders, ${ }^{2,6,7}$ which was not replicated in our study. Female predominance $(74 \%)$ in our sample may explain this inconsistency.

The irritable and hyperthymic temperaments were higher in the AUD group than in the non-AUD group. However, when adjusting diagnosis and other confounding variables, these did not predict AUD. The predominance of BD subjects in the AUD group (83\%) may explain the group differences. Only one study by Singh et al. ${ }^{29}$ explored affective temperaments in comorbid AUD and BD. In their study, irritable and hyperthymic temperaments independently predicted AUD in subjects with BD. Possible explanations for this inconsistency include characteristics of the sample and study design. Sub- 
Table 2. Regression model 1 including sex, age, severity of mood symptoms, affective temperaments, childhood trauma, and suicidal ideation as covariates

\begin{tabular}{|c|c|c|c|c|c|}
\hline & \multirow{2}{*}{ OR } & \multicolumn{2}{|c|}{$95 \% \mathrm{CI}$ of $\mathrm{OR}$} & \multirow{2}{*}{$\mathrm{p}$} & \multirow{2}{*}{ SE } \\
\hline & & Lower limit & Upper limit & & \\
\hline Female & 0.415 & 0.119 & 1.446 & 0.167 & 0.638 \\
\hline Age & 1.080 & 1.010 & 1.154 & 0.023 & 0.034 \\
\hline Diagnosis of $\mathrm{BD}$ & 1.521 & 0.390 & 5.926 & 0.546 & 0.694 \\
\hline HAMD & 1.040 & 0.946 & 1.143 & 0.415 & 0.048 \\
\hline YMRS & 1.110 & 0.987 & 1.248 & 0.081 & 0.060 \\
\hline Cyclothymic temperament & 1.092 & 0.886 & 1.346 & 0.411 & 0.107 \\
\hline Depressive temperament & 0.946 & 0.711 & 1.258 & 0.704 & 0.145 \\
\hline Irritable temperament & 1.275 & 0.914 & 1.779 & 0.152 & 0.170 \\
\hline Hyperthymic temperament & 1.236 & 0.974 & 1.569 & 0.082 & 0.122 \\
\hline Anxious temperament & 0.373 & 0.206 & 0.675 & 0.001 & 0.303 \\
\hline CTQ & 1.048 & 1.017 & 1.080 & 0.002 & 0.015 \\
\hline SSI & 1.062 & 0.990 & 1.138 & 0.095 & 0.036 \\
\hline
\end{tabular}

BD: bipolar disorder, HAMD: Hamilton Depression Rating Scale, YMRS: Young Mania Rating Scale, SSI: Scale for Suicide Ideation, CTQ: Childhood Trauma Questionnaire

Table 3. Regression model 2 including sex, age, diagnosis, and dimensions of mood symptoms as covariates

\begin{tabular}{|c|c|c|c|c|c|}
\hline & \multirow{2}{*}{ OR } & \multicolumn{2}{|c|}{$95 \% \mathrm{CI}$ of $\mathrm{OR}$} & \multirow{2}{*}{$\mathrm{p}$} & \multirow{2}{*}{ SE } \\
\hline & & Lower limit & Upper limit & & \\
\hline Female & 0.629 & 0.220 & 1.798 & 0.387 & 0.536 \\
\hline Age & 0.986 & 0.943 & 1.030 & 0.518 & 0.023 \\
\hline Diagnosis of $\mathrm{BD}$ & 3.677 & 1.031 & 13.119 & 0.045 & 0.649 \\
\hline Somatic anxiety of HAMD & 0.948 & 0.774 & 1.161 & 0.607 & 0.104 \\
\hline Psychic anxiety of HAMD & 1.155 & 0.882 & 1.514 & 0.295 & 0.138 \\
\hline Core depression of HAMD & 1.032 & 0.814 & 1.308 & 0.798 & 0.121 \\
\hline Anorexia of HAMD & 1.318 & 0.817 & 2.126 & 0.257 & 0.244 \\
\hline Irritable mania of YMRS & 1.412 & 1.162 & 1.717 & 0.001 & 0.100 \\
\hline Elated mania of YMRS & 0.960 & 0.667 & 1.381 & 0.825 & 0.186 \\
\hline Psychotic Mania of YMRS & 0.759 & 0.467 & 1.234 & 0.266 & 0.248 \\
\hline
\end{tabular}

BD: bipolar disorder, HAMD: Hamilton Depression Rating Scale, YMRS: Young Mania Rating Scale

jects in our study were in a depressive episode, while mood states of subjects in the study by Singh et al..$^{29}$ were not uniform. The severity of depressive symptoms in their study was much lower than that in our study. Reports by subjects may be influenced by their mood states. In depressed subjects, subjective reports of 'up' signs may be attenuated and those of 'down' signs may be exaggerated. The trends of differences in raw scores are quite similar between the two results. However, the scores of depressive temperament were 4.0 vs. 3.7 in our sample and were 2.7 vs. 2.2 in Singh et al. ${ }^{29}$ Another explanation may be related to statistical power. The sample size in our study was much smaller than that in Singh et al. ${ }^{29}$ study.

The protective effect of anxious temperament was a unique and unexpected finding. There are few studies on the role of anxious temperament in AUD in mood disorders. In previous studies on substance use disorders, anxious temperament was a risk factor, ${ }^{30,48}$ which ran contrary to our findings. However, we can assume that the functional roles of anxious temperament may be distinct from different conditions. Anxious temperament correlates positively with harm avoidance and negatively with novelty seeking, ${ }^{41}$ which is exactly opposite to hyperthymic temperament. High novelty seeking is related to increased alcohol use while high harm avoidance with abstinence. ${ }^{49}$ Therefore, it seems logical to say that anxious temperament is related to low drinking and hyperthymic temperament is related to high drinking, according to Cloninger's temperament dimensions. In this context, we may hypothesize that, in a depressed state, hyperthymic temperament may 
play a less significant role and anxious temperament play a more important role than in euthymic or euphoric states. The significant effect of anxious temperament was independent of childhood trauma that was another risk for AUD. Childhood trauma may cause a range of mental disorders including depression, alcohol misuse and suicidal attempts..$^{50}$ Our results add further evidence that childhood adversities may complicate the course of mood disorder.

Regarding mood symptoms, none of the depressive symptom dimensions were found to be associated with AUD. Combined with findings of previous studies, ${ }^{23-26}$ it seems that there are little connections between specific depressive symptoms and AUD in mood disorder. The severity of depression was not associated with AUD as well. On the other hand, mixed depressive state was more frequent in the AUD group and the severity of manic symptoms and irritable manic symptoms were associated with AUD. In particular, the irritable manic symptom dimension predicted AUD independently of BD diagnosis. These findings may implicate that AUD in mood disorders may relate to manic components but not to depressive components. Evidence from previous studies supports our findings, such as more frequent addictive disorders in the mixed episodes rather than the pure depressive episodes, ${ }^{51}$ drinkings resulting from manic severity, ${ }^{52,53}$ and increased predisposition to impulsivity in $\mathrm{BD}$ comorbid with substance use. ${ }^{54}$

Whilst the current study has strengths over previous studies in that we have focused on depressive state and assessed systematic confounders, several limitations should be noted. Firstly, the sample size was not large enough to ensure subgroup analyses and to show sufficient statistical power. In future studies, subtypes of $\mathrm{BD}$, specifiers of depressive episodes or courses need to be considered. Secondly, our analyses were limited to co-occurring AUD to magnify the phenomena during a depressive episode. Lifetime comorbidity, temporal sequence of the onset, and longitudinal courses should be further explored. Thirdly, data were collected from a single-center, which limits the generalizability of the findings. Characteristics of subjects such as younger age and female predominance make a direct comparison with findings from previous studies difficult. Other limitations include the reliability of TEMPS-A. The authors did not validate the translated version. However, authors who are experienced in this field confirmed the face validity and empirically found the usefulness of the measure. Despite these limitations, our findings offer an important insight into understanding AUD found in depressed patients.

In conclusion, co-occurring AUD during depression was associated with a diagnosis of $\mathrm{BD}$, the severity of manic symptoms and irritability symptoms. Among affective tem- peraments, anxious temperament played a protective role. Our findings suggest that, even during depression, alcohol use may be an expression of manic symptom dimension.

\section{Acknowledgments}

This study was supported by a grant 11-2011-029 from the Seoul National University Bundang Hospital Research Fund.

\section{Conflicts of Interest}

The authors have no potential conflicts of interest to disclose.

\section{Author Contributions}

Conceptualization: Minseok Hong, Tae Hyon Ha. Data curation: Minseok Hong, Suyeon Lee, Sunghee Oh. Formal analysis: Minseok Hong. Funding acquisition: Tae Hyon Ha. Investigation: Tae Hyon Ha, Suyeon Lee, Woojae Myung. Methodology: Minseok Hong, Tae Hyon Ha. Project administration: Tae Hyon Ha, Suyeon Lee, Sunghee Oh. Resources: Tae Hyon Ha, Woojae Myung. Software: Minseok Hong. Supervision: Tae Hyon Ha. Validation: Tae Hyon Ha. Visualization \& Writing-original draft: Minseok Hong. Writing-review \& editing: Tae Hyon Ha.

\section{ORCID iDs}

Tae Hyon Ha

Minseok Hong

https://orcid.org/0000-0002-2778-6619

https://orcid.org/0000-0001-6028-8286

\section{REFERENCES}

1. Cassidy F, Ahearn EP, Carroll BJ. Substance abuse in bipolar disorder. Bipolar Disord 2001;3:181-188.

2. Frye MA, Altshuler LL, McElroy SL, Suppes T, Keck PE, Denicoff K, et al. Gender differences in prevalence, risk, and clinical correlates of alcoholism comorbidity in bipolar disorder. Am J Psychiatry 2003;160: 883-889.

3. Levander E, Frye MA, McElroy S, Suppes T, Grunze H, Nolen WA, et al. Alcoholism and anxiety in bipolar illness: differential lifetime anxiety comorbidity in bipolar I women with and without alcoholism. J Affect Disord 2007;101:211-217.

4. McElroy SL, Altshuler LL, Suppes T, Keck PE Jr, Frye MA, Denicoff $\mathrm{KD}$, et al. Axis I psychiatric comorbidity and its relationship to historical illness variables in 288 patients with bipolar disorder. Am J Psychiatry 2001;158:420-426.

5. Winokur G, Coryell W, Akiskal HS, Maser JD, Keller MB, Endicott J, et al. Alcoholism in manic-depressive (bipolar) illness: familial illness, course of illness, and the primary-secondary distinction. Am J Psychiatry 1995;152:365-372.

6. Boschloo L, Vogelzangs N, Smit JH, van den Brink W, Veltman DJ, Beekman AT, et al. Comorbidity and risk indicators for alcohol use disorders among persons with anxiety and/or depressive disorders: findings from the Netherlands Study of Depression and Anxiety (NESDA). J Affect Disord 2011;131:233-242.

7. Hasin DS, Stinson FS, Ogburn E, Grant BF. Prevalence, correlates, disability, and comorbidity of DSM-IV alcohol abuse and dependence in the United States: results from the National Epidemiologic Survey on Alcohol and Related Conditions. Arch Gen Psychiatry 2007;64:830-842.

8. Briere FN, Rohde P, Seeley JR, Klein D, Lewinsohn PM. Comorbidity between major depression and alcohol use disorder from adolescence to adulthood. Compr Psychiatry 2014;55:526-533.

9. DelBello MP, Hanseman D, Adler CM, Fleck DE, Strakowski SM. Twelve-month outcome of adolescents with bipolar disorder following first hospitalization for a manic or mixed episode. Am J Psychiatry 2007;164:582-590.

10. Simhandl C, Radua J, Konig B, Amann BL. Prevalence and impact of comorbid alcohol use disorder in bipolar disorder: a prospective follow-up study. Aust N Z J Psychiatry 2016;50:345-351. 
11. Oquendo MA, Currier D, Liu SM, Hasin DS, Grant BF, Blanco C. Increased risk for suicidal behavior in comorbid bipolar disorder and alcohol use disorders: results from the National Epidemiologic Survey on Alcohol and Related Conditions (NESARC). J Clin Psychiatry 2010;71:902-909.

12. Salloum IM, Cornelius JR, Mezzich JE, Kirisci L. Impact of concurrent alcohol misuse on symptom presentation of acute mania at initial evaluation. Bipolar Disord 2002;4:418-421.

13. Baldessarini RJ, Perry R, Pike J. Factors associated with treatment nonadherence among US bipolar disorder patients. Hum Psychopharmacol 2008;23:95-105.

14. Yoon YH, Chen CM, Yi HY, Moss HB. Effect of comorbid alcohol and drug use disorders on premature death among unipolar and bipolar disorder decedents in the United States, 1999 to 2006. Compr Psychiatry 2011;52:453-464.

15. Sullivan LE, Fiellin DA, O'Connor PG. The prevalence and impact of alcohol problems in major depression: a systematic review. Am J Med 2005;118:330-341.

16. Hobden B, Bryant J, Carey M, Baker AL, Farrell M, Oldmeadow C, et al. Finding the optimal treatment model: a systematic review of treatment for co-occurring alcohol misuse and depression. Aust N Z J Psychiatry 2018;52:737-750.

17. Salloum IM, Brown ES. Management of comorbid bipolar disorder and substance use disorders. Am J Drug Alcohol Abuse 2017;43:366-376.

18. Beaulieu S, Saury S, Sareen J, Tremblay J, Schutz CG, McIntyre RS, et al. The Canadian Network for Mood and Anxiety Treatments (CANMAT) task force recommendations for the management of patients with mood disorders and comorbid substance use disorders. Ann Clin Psychiatry 2012;24:38-55.

19. Boden JM, Fergusson DM. Alcohol and depression. Addiction 2011; 106:906-914.

20. Bolton JM, Robinson J, Sareen J. Self-medication of mood disorders with alcohol and drugs in the National Epidemiologic Survey on Alcohol and Related Conditions. J Affect Disord 2009;115:367-375.

21. Gomez-Coronado N, Sethi R, Bortolasci CC, Arancini L, Berk M, Dodd S. A review of the neurobiological underpinning of comorbid substance use and mood disorders. J Affect Disord 2018;241:388-401.

22. Nery FG, Miranda-Scippa A, Nery-Fernandes F, Kapczinski F, Lafer B. Prevalence and clinical correlates of alcohol use disorders among bipolar disorder patients: results from the Brazilian Bipolar Research Network. Compr Psychiatry 2014;55:1116-1121.

23. Blanco C, Alegria AA, Liu SM, Secades-Villa R, Sugaya L, Davies C, et al. Differences among major depressive disorder with and without cooccurring substance use disorders and substance-induced depressive disorder: results from the National Epidemiologic Survey on Alcohol and Related Conditions. J Clin Psychiatry 2012;73:865-873.

24. Carton L, Pignon B, Baguet A, Benradia I, Roelandt JL, Vaiva G, et al. Influence of comorbid alcohol use disorders on the clinical patterns of major depressive disorder: a general population-based study. Drug Alcohol Depend 2018;187:40-47.

25. Cornelius JR, Salloum IM, Mezzich J, Cornelius MD, Fabrega H Jr, Ehler JG, et al. Disproportionate suicidality in patients with comorbid major depression and alcoholism. Am J Psychiatry 1995;152:358-364.

26. Davis LL, Frazier E, Husain MM, Warden D, Trivedi M, Fava M, et al. Substance use disorder comorbidity in major depressive disorder: a confirmatory analysis of the STAR ${ }^{\star} \mathrm{D}$ cohort. Am J Addict 2006;15:278-285.

27. Kraepelin E. Manic-Depressive Insanity and Paranoia. New York: Arno Press; 1976.

28. Akiskal HS, Akiskal KK. In search of Aristotle: temperament, human nature, melancholia, creativity and eminence. J Affect Disord 2007;100:1-6.

29. Singh S, Forty L, di Florio A, Gordon-Smith K, Jones I, Craddock N, et al. Affective temperaments and concomitant alcohol use disorders in bipolar disorder. J Affect Disord 2015;186:226-231.

30. Khazaal Y, Gex-Fabry M, Nallet A, Weber B, Favre S, Voide R, et al. Affective temperaments in alcohol and opiate addictions. Psychiatr Q
2013;84:429-438.

31. Leite L, Machado LN, Lara DR. Emotional traits and affective temperaments in alcohol users, abusers and dependents in a national sample. J Affect Disord 2014;163:65-69.

32. Pacini M, Maremmani I, Vitali M, Santini P, Romeo M, Ceccanti M. Affective temperaments in alcoholic patients. Alcohol 2009;43:397-404.

33. Vyssoki B, Bluml V, Gleiss A, Friedrich F, Kogoj D, Walter H, et al. The impact of temperament in the course of alcohol dependence. J Affect Disord 2011;135:177-183.

34. Darke S. Pathways to heroin dependence: time to re-appraise selfmedication. Addiction 2013;108:659-667.

35. Enoch MA. The role of early life stress as a predictor for alcohol and drug dependence. Psychopharmacology (Berl) 2011;214:17-31.

36. Schuck AM, Widom CS. Childhood victimization and alcohol symptoms in females: causal inferences and hypothesized mediators. Child Abuse Negl 2001;25:1069-1092.

37. Salokangas RKR, From T, Luutonen S, Salokangas HRW, Hietala J. Effect of childhood adversities on alcohol problems is mainly mediated by depression. Am J Addict 2018 [Epub ahead of print].

38. Sheehan DV, Lecrubier Y, Sheehan KH, Amorim P, Janavs J, Weiller E, et al. The Mini-International Neuropsychiatric Interview (M.I.N.I.): the development and validation of a structured diagnostic psychiatric interview for DSM-IV and ICD-10. J Clin Psychiatry 1998;59(Suppl 20):22-33;quiz 34-57.

39. Beck AT, Brown GK, Steer RA. Psychometric characteristics of the Scale for Suicide Ideation with psychiatric outpatients. Behav Res Ther 1997;35:1039-1046.

40. Kim D, Park SC, Yang H, Oh DH. Reliability and validity of the Korean version of the childhood trauma questionnaire-short form for psychiatric outpatients. Psychiatry Investig 2011;8:305-311.

41. Akiskal HS, Mendlowicz MV, Jean-Louis G, Rapaport MH, Kelsoe JR, Gillin JC, et al. TEMPS-A: validation of a short version of a self-rated instrument designed to measure variations in temperament. J Affect Disord 2005;85:45-52.

42. Colman I, Garad Y, Zeng Y, Naicker K, Weeks M, Patten SB, et al. Stress and development of depression and heavy drinking in adulthood: moderating effects of childhood trauma. Soc Psychiatry Psychiatr Epidemiol 2013;48:265-274.

43. Vitriol V, Cancino A, Leiva-Bianchi M, Serrano C, Ballesteros S, Asenjo A, et al. Childhood trauma and psychiatric comorbidities in patients with depressive disorder in primary care in Chile. J Trauma Dissociation 2017;18:189-205.

44. Sung YK, La Flair LN, Mojtabai R, Lee LC, Spivak S, Crum RM. The association of alcohol use disorders with suicidal ideation and suicide attempts in a population-based sample with mood symptoms. Arch Suicide Res 2016;20:219-232.

45. Salokangas RKR, Luutonen S, Heinimaa M, From T, Hietala J. A study on the association of psychiatric diagnoses and childhood adversities with suicide risk. Nord J Psychiatry 2019;73:125-131.

46. Pancheri P, Picardi A, Pasquini M, Gaetano P, Biondi M. Psychopathological dimensions of depression: a factor study of the 17-item Hamilton depression rating scale in unipolar depressed outpatients. J Affect Disord 2002;68:41-47.

47. Hanwella R, de Silva VA. Signs and symptoms of acute mania: a factor analysis. BMC Psychiatry 2011;11:137.

48. Yehya Y, Haddad C, Obeid S, Tahan F, Nabout R, Hallit S, et al. Affective temperaments in Lebanese people with substance use disorder. Perspect Psychiatr Care 2019;55:478-485.

49. Vladimirov D, Niemela S, Keinanen-Kiukaanniemi S, Ala-Mursula L, Auvinen J, Timonen M, et al. Cloninger's temperament dimensions and longitudinal alcohol use in early midlife: a Northern Finland birth cohort 1966 study. Alcohol Clin Exp Res 2018;42:1924-1932.

50. Norman RE, Byambaa M, De R, Butchart A, Scott J, Vos T. The longterm health consequences of child physical abuse, emotional abuse, and neglect: a systematic review and meta-analysis. PLoS Med 2012; 


$$
\text { 9:e1001349. }
$$

51. Keller MB, Lavori PW, Coryell W, Andreasen NC, Endicott J, Clayton PJ, et al. Differential outcome of pure manic, mixed/cycling, and pure depressive episodes in patients with bipolar illness. JAMA 1986;255:3138-3142.

52. Azorin JM, Kaladjian A, Adida M, Fakra E, Hantouche E, Lancrenon S. Correlates of first-episode polarity in a French cohort of 1089 bipolar I disorder patients: role of temperaments and triggering events. J
Affect Disord 2011;129:39-46.

53. Horwitz SM, Storfer-Isser A, Young AS, Youngstrom EA, Taylor HG, Frazier TW, et al. Development of alcohol and drug use in youth with manic symptoms. J Am Acad Child Adolesc Psychiatry 2017;56:149-156.

54. Swann AC, Dougherty DM, Pazzaglia PJ, Pham M, Moeller FG. Impulsivity: a link between bipolar disorder and substance abuse. Bipolar Disord 2004;6:204-212. 